\title{
INFLUENCE OF THE THICKNESS OF NI-P COATING APPLIED ON 7075 ALUMINUM ALLOY ON ITS HARDNESS
}

\author{
Kazimierz Czapczyk ${ }^{1}$, Piotr Siwak', Piotr Jablonski' ${ }^{1}$, \\ Lukasz Furmanski', Pawel Grobelny', Stanislaw Legutko'
}

1 Poznan University of Technology, Faculty of Mechanical Engineering and Management, 3 Piotrowo Str., 60-965 Poznan, Poland, e-mail: kazimierz.czapczyk@put.poznan.pl, piotr.siwak@put.poznan.pl, piotr.jablonski@put. poznan.pl, lukasz.furmanski@put.poznan.pl, pawel.grobelny@put.poznan.pl, stanislaw.legutko@put.poznan.pl

Received: 2016.08 .31 Accepted: 2016.10 .08 Published: 2016.12.01

\begin{abstract}
The paper presents the results of hardness tests of aluminum alloy AW-7075 (for plastic processing) and Ni-P chemical coatings (nickel-phosphorus) which had been applied by the no-current method. Coatings of various thickness have been made and their influence on the increase of the top layer hardness has been determined, as well as the increase of the hardness of the coating and substrate system after puncturing the coating with an indenter. The purpose of the investigation was to determine the possibility of applying the Ni-P coating for selected technical applications, among others, by the selection of its optimum thickness on the hard aluminum alloy and by the determination of the deformation resistance of the top layer if the given coating.
\end{abstract}

Keywords: aluminum alloy AW-7075, Ni-P coating, hardness.

\section{INTRODUCTION}

The investigation objective is to determine to what extent aluminum alloys of the system Al$\mathrm{Zn}-\mathrm{Mg}$ with medium phosphorus content are suitable for selected technical applications. The Ni-P chemical coating are one of the few which can be successfully applied on those alloys (and on other materials, too) of technical destination. The survey of literature and scientific publications have shown that the investigations are focused on anticorrosion protection of steel materials and it is hard to find examples of the application of Ni-P coatings on machine parts made of aluminum alloys which are exposed to friction or cyclically repeated pressures. There are also many decorative coatings for aluminum alloys, however they are not suitable for loaded machine parts regardless of the kind of substrate. Besides it, to ensure better surface integrity, special attention must be paid when choosing process parameters $[1,2]$, and tool coatings $[3,4]$.
Obviously, attempts are made to conduct tribological investigation of the use of coatings for technical purposes (other than anticorrosive ones), e.g. by application of a composite antiwear layer type Ni-P- $\mathrm{Al}_{2} \mathrm{O}_{3}$ on $\mathrm{C} 45$ steel. Scientists investigating this kind of coatings indicate that increasing tribological properties, i.e. counteracting friction wear of machine elements is still an issue of great importance in technology; composite materials are the most promising and developing group of materials enjoying much interest in research and application works. Furthermore, nickel coatings on steel elements play the function of antiwear top layers. In many exploitation applications, the function is boosted by the use of lubricant substances containing modifying additives type FM and AW [5].

\section{DESCRIPTION OF THE AW-7075 ALLOY}

Although aluminum has many very good utilization properties, its strength properties are 
relatively low (the yield point of pure aluminum is about $7-11 \mathrm{MPa}$ ), which limits the use of it as a constructional material. In order to improve its strength properties, aluminum is enriched with various alloy additives, subjected to heat treatment and consolidated. Due to that, much better strength can be obtained (as much as several dozen times higher). An example is the AW-7075 alloy (high hardness of up to about $190 \mathrm{HB}$, low density of about $2.81 \mathrm{~g} / \mathrm{cm}^{3}$ ). The material constant values are close to those of steel; the yield point and tensile strength are also very good $\left(\mathrm{R}_{\mathrm{e}}=\right.$ $390-470 \mathrm{MPa}, \mathrm{R}_{\mathrm{m}}=480-540 \mathrm{MPa}$ ).

The AW- 7075 alloy is widely used in the world industry and it is important, first of all, in the production of aircrafts [6]. Aluminum alloys are also used in shipbuilding. For example, they are applied in building hulls of small ships and warships of high sailing speed, as well as superstructures and various shop equipment. The application of aluminum alloys in the construction of ship hulls is due to the fact that the alloys allow the mass of ship construction much less as compared to that of steel constructions. By the use of aluminum alloys, mass reduction of about $50 \%$ can be obtained, which allows for reduction of the ship displacement or, with the displacement maintained, for increasing its cargo deadweight or speed, as well as for improvement of its stability. For those reasons, aluminum alloys are used in building displacement ships and also such ones as air cushion vehicles or hydrofoil ships. In addition to the above mentioned mass advantages, aluminum alloys have many other features which enable them to be used in shipbuilding. In the present day shipbuilding industry, in such constructions as hull sheathing are made with the use of $5 \mathrm{xxx}$ series (Al-Mg). The most popular one is 5083 alloy having medium strength properties and good resistance to corrosion, particularly stress corrosion. In the nineties, weld able alloys of the $7 \mathrm{xxx}$ series (Al-Zn-Mg) enjoyed much interest, having much higher strength properties as compared to the $5 \mathrm{xxx}$ series alloys. A drawback of the Al-Zn-Mg alloys is their susceptibility to corrosion cracking in the sea water environment, especially when the total $\mathrm{Zn}-\mathrm{Mg}$ content exceeds $6 \%$ [7].

AW-7075 alloys are still most often investigated aluminum alloys. The high strength of those materials, which has contributed to their industrial applications, has been obtained, to a large extent by the chemical composition additives, such as, for example $\mathrm{Cu}$ [6]. Selection of adequate Ni-P coating thickness, possible heat treatment and optimum configuration of the coating chemical composition would enable the 7075 alloy to be used for responsible machine parts.

\section{GENERAL CHARACTERISTICS OF THE NO-CURRENT ANTIWEAR NI-P COATING}

The no-current coatings obtained as a result of reduction on nickel ions by means of hydro phosphate contain nickel and phosphorus. The coating material is unique due to the method of applying and its properties. The nickel-phosphorus coatings are amorphous, homogenous, hard, relatively brittle, self-lubricating, easy-to-solder and have good corrosion resistance. Furthermore, they can be significantly precipitate strengthened. As result, the nickel-phosphorus coatings are suitable for many applications. Hardness of the nickel-phosphorus coating applied by the nocurrent method is about $500-600 \mathrm{HV}$. During heat treatment consisting in ageing at the temperature of $340{ }^{\circ} \mathrm{C}$ for 2 hours the hardness of the coating increases up- to as much as $1100 \mathrm{HV}$. Strengthening in the process of ageing is due to the precipitation of nickel phosphide. The nickelphosphorus coatings applied by the no-current method, due to their high hardness, have good abrasive wear resistance, both just after application and in the hardened condition. Furthermore, the nickel coating protects the substrate against corrosion insulating it from the environment due to its amorphous nature - the corrosion resistance is better than that of pure $\mathrm{Ni}$ and $\mathrm{Cr}$ alloys [8]. Compared to the nickel coatings obtained by the galvanic method, the ones obtained by the chemical method show the following major advantages:

- the nickel coating forms a layer of the same thickness on all the surfaces reached by the bath, regardless of the shape of the object being coated,

- the coating structure is uniform and independent from the substrate structure,

- they have higher hardness which can be increased by subsequent heat treatment,

- they have better corrosion resistance,

- they can be applied directly on aluminum,

- they show good solderabillity.

The coating under discussion is formed by solid solution of phosphorus (7-10\%) in nickel. 
The process of chemical nickel coating extends the range of application of nickel coatings but, for economic reasons, it has some drawbacks, too:

- the cost of the chemical nickel coating bath components which is higher than in the case of galvanic bath,

- the major difficulty in wide application of chemical nickel coating is regeneration of the bath [9].

Considering the possibilities of applying the Ni-P coating on aluminum alloys for technical use, with the incorporation of its properties, advantages and many tests performed so far, among others by the Institute of Precision Mechanics in Warsaw (Poland), the coating is suitable for tribological tests in the application for machine parts made of the aluminum alloy AW-7075.

\section{THE PURPOSE AND METHODOLOGY OF EXPERIMENTAL TESTS}

Aerological systems are elaborated and applied, first of all, because none of the elements of the aerological system is not able to ensure the complex of the required properties, while in combination - forming a composite - due to synergetic interaction of the elements, the system can ensure the required properties. The requirements of the synergism of the elements necessitate the application of adequate compositions of the aerological system components. In the design of the aerological system under consideration, the following simple composition has been adopted: hard substrate of aluminum alloy (ground to obtain adequate roughness) has been covered with Ni-P coating harder than the substrate. Grinding prior to the coating application has been applied to obtain adequately strong joints between the elements of the aerological system elements, particularly between the surface layer and the coating. Thanks to that, gradient character of properties for surface layer and coatings has been obtained. Furthermore, the system of the surface layer and coating where the surface layer has not been modified (only such execu- tion of it has been considered as results from the forming technology, i.e. machining) makes the so called triplex model in the developed model of the aerological system, that is root + top layer + coating [10]. Laboratory tests have been performed on two different devices, among others, one for hardness testing. The hardness of the coatings themselves, as well as that of the coating and substrate system (in addition to adhesion, surface roughness and fatigue strength) is very important in respect of abrasive wear resistance, especially plastic deformation of the surface layer which results in variation of the working surface shape. Adequately high hardness is one of the parameters limiting the disadvantageous phenomenon of wear.

The material on which the coatings have been made was aluminum alloy AW-7075 prepared for the tests in the form of samples dimensioned $15 \times 15 \times 7 \mathrm{~mm}$ which can be seen in Fig. 1. The chemical composition of the alloy has been shown in Table 1.

Next, the samples have been coated with the chemical coating of nickel-phosphorus (Ni-P) by the no-current method. When preparing the galvanic bath, phosphorus content in the coating was applied (about $7-10 \%$ ). Prior to that, the sample surfaces were ground with abrasive paper grade 1200; then immediately after submission of the samples to galvanic technology company, GALVO S.A. in Łódź, the samples were degreased, etched and washed in order to obtain the best adhesion and to avoid defects of the Ni-P coatings. Part of the samples were not coated, another part

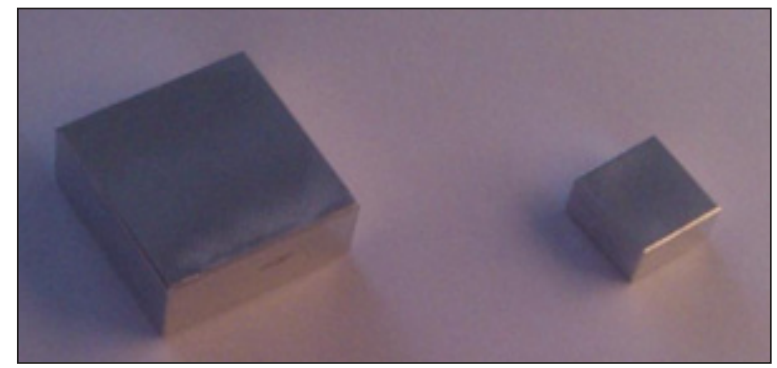

Fig. 1. Samples made of 7975 alloy (Fortal) prior to the application of the no-current Ni-P coating

Table 1. Chemical composition of the AW-7075 alloy

\begin{tabular}{|c|c|c|c|c|c|c|c|c|c|c|}
\hline $\begin{array}{c}\mathrm{Al} \\
{[\%]}\end{array}$ & $\begin{array}{c}\mathrm{Zn} \\
{[\%]}\end{array}$ & $\begin{array}{c}\mathrm{Mg} \\
{[\%]}\end{array}$ & $\begin{array}{c}\mathrm{Cu} \\
{[\%]}\end{array}$ & $\begin{array}{c}\mathrm{Fe} \\
{[\%]}\end{array}$ & $\begin{array}{c}\mathrm{Si} \\
{[\%]}\end{array}$ & $\begin{array}{c}\mathrm{Mn} \\
{[\%]}\end{array}$ & $\begin{array}{c}\mathrm{Cr} \\
{[\%]}\end{array}$ & $\begin{array}{c}\mathrm{Zr} \\
{[\%]}\end{array}$ & $\begin{array}{c}\mathrm{Ti} \\
{[\%]}\end{array}$ & $\begin{array}{c}\text { Others } \\
{[\%]}\end{array}$ \\
\hline Rest & $5.1-6.1$ & $2.1-2.9$ & $1.2-2.0$ & $\max$ & $\max$ & $\max$ & $0.18-$ & $\max$ & $\max$ & $\max 0.05$ \\
\hline
\end{tabular}


was divided into groups were covered with Ni-P coatings of various thicknesses. The samples prepared in this way were subjected to hardness tests by the Vickers method on two devices: FV-700 and PICODENTOR HM500. In the first stage, the hardness of the samples themselves (without coatings) has been tested on the FV-700 device and the average results were obtained at the level of 155 HV. The load of the indenter $\left(\alpha=136^{\circ}\right)$ was $1 \mathrm{~kg}$ in a time of 9 seconds. Hardness was measured in three rows and the indentations were made at even intervals. In the second stage of testing, the hardness of the coating made (in accordance with the galvanic technology) directly on aluminum alloys, AW-7075 (with the hardness of about $155 \mathrm{HV}$ ) has been performed. The following coating thicknesses have been selected: 10,20 and $30 \mu \mathrm{m}$ - due to the fact that with those thicknesses the Ni-P coatings maintain their best stiffness and adhesion to the substrate and, at the same time they form homogenous, even and stable separation of the aluminum alloy from the ambient conditions. Vickers hardness tests were performed with the use of laboratory nano hardness tester, PICODENTOR HM500 and the measurements were effected with the indenter load of $300[\mathrm{mN}]$ in a period of 20 seconds. Hardness tests were performed in three rows so as to make the indentations at sufficient equal distances from each other.

The next stage of investigation included hardness tests of the system of coatings made directly on aluminum alloys AW-7075 with the hardness of about $155 \mathrm{HV}$ with the substrate material, i.e. the sample coating was punctured with the indenter. For this purpose, the standard semiautomatic hardness tester FV-700 was used for HV1 in a period of 9 seconds $\left(\alpha=136^{\circ}\right)$. Hardness measurements were performed in the same way as in the previous stage.

Ni-P coating applied on the AW-7075 alloy (which is a very hard material) has clearly higher hardness than the substrate material and, as compared to the core material, its hardness grows gradually up to the value of about $600 \mathrm{HV}$.

\section{HARDNESS TEST RESULTS}

On each sample, 5 measurements were performed at even intervals in several rows maintaining the distance of at least $2 \mathrm{~mm}$ from the edge of the samples. when the measurement results have been obtained, average values of them were calculated, recorded in Table 2 and depicted in a block diagram (Fig. 2).

Table 2. Average values of hardness measurement results for samples of AW-7075 aluminum alloy

\begin{tabular}{|c|c|c|c|}
\hline Sample No. & Ni-P coating thickness & $\begin{array}{c}\text { Macro hardness } \\
{[\mathrm{N} / \mathrm{mm} 2]}\end{array}$ & $\begin{array}{c}\text { Nano hardness HV of the coating } \\
{[\mathrm{N} / \mathrm{mm} 2]}\end{array}$ \\
\hline A1 & 0 (no coating) & 155 & - \\
\hline A2 & 10 & 221,56 & 597,96 \\
\hline A3 & 20 & 374,14 & 735,28 \\
\hline A4 & 30 & 414,92 & 935,42 \\
\hline
\end{tabular}

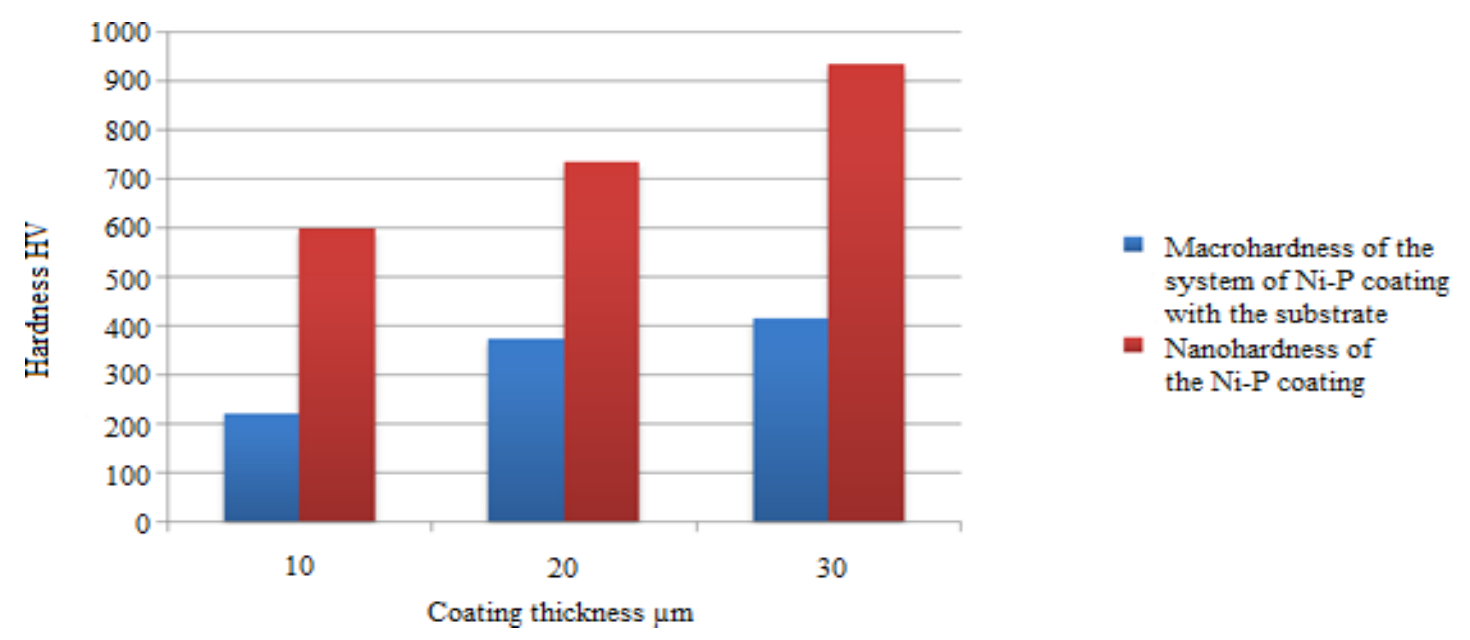

Fig. 2. Diagram of Vickers hardness of the Ni-P coating on aluminum alloy AW-7075 
Hardness tests have shown significant increase of the hardness of the coated surface layers as compared to the hardness of the AW-7075 aluminum alloy and that increase is clearly depicted in Figure 2; it can also be seen from the figure that the coating hardness grow with the increase of their thickness and, in some measurements of the coatings alone results above 1000 $\mathrm{HV}$ were obtained although they were mostly in the region of hardness limit above 900 HV. For each thickness, multiple hardness increases were obtained (4 to 9) as compared to the AW-7075 alloy on which the Ni-P coatings had been made. That is a very good basis for further tribological tests in respect of the Ni-P coating application or its modification.

\section{COMPARATIVE ANALYSIS OF THE RESULTS}

Comparative analysis in respect of hardness was performed in comparison to actual gear wheels taken out of a hipoidal gear of a generator drive which is commonly used in rail vehicles for electrical supply of them; the generated power is about $6000 \mathrm{~W}$. The toothed wheels
(Fig. 3) which are used in the generator drive gear are made of ordinary constructional steel, which additionally proved by hardness tests performed by the laboratory of the Poznan University of Technology, Poznan (Poland). The results of hardness tests of the gear wheels are presented in Table 3 [11].

Prior to the hardness measurement, the part shown in Fig. 3 has been divided in such a way as to make it possible to test it precisely in several places by various methods. Hardness at the level of $300 \mathrm{HV}$ indicates much similarity to the macro hardness of the system of the Ni-P with the substrate applied on aluminum alloy with the hardness of $155 \mathrm{HV}$, however, a more adequate comparison is reference to the nano hardness of coatings because, in this test, the bonds between the elements of the aerological system have not been disturbed, i.e. the coating has not been completely pierced with the indenter and the bond between the surface layer and the coating has been properly maintained. If sufficiently strong bond between the surface layer and the coating were obtained, e.g. by adequate modification of the top layer, theoretically the toothed wheels could be substituted with aluminum wheels with antiwear coating of adequate properties.

Table 3. Vickers and Rockwell hardness measurement results of steel toothed wheel of a generator drive [11]

\begin{tabular}{|c|c|c|c|c|}
\hline \multicolumn{5}{|c|}{ Hardness } \\
\hline Measurement & $\begin{array}{c}\text { HV1 } \\
{[\mathrm{N} / \mathrm{mm} 2]}\end{array}$ & HRC & $\begin{array}{c}\text { HV5 } \\
{[\mathrm{N} / \mathrm{mm} 2]}\end{array}$ & HRC \\
\hline 1 & 308,7 & 30,08 & 306,4 & 30,5 \\
\hline 2 & 308,3 & 30,7 & 322 & 32 \\
\hline 3 & 307,9 & 30,7 & 273,9 & 26 \\
\hline Average & 308,3 & 30,5 & 300,8 & 29,5 \\
\hline
\end{tabular}

\section{DISCUSSION}

The diagram (Fig. 2) shows that the hardness of the coating surface layer is clearly higher than that of the aluminum alloy AW-7075. Furthermore, the hardness values can be seen to grow gradually with the increase of the Ni-P coating thickness and in some measurements, results above $1000 \mathrm{HV}$ have been obtained and they keep in the region of

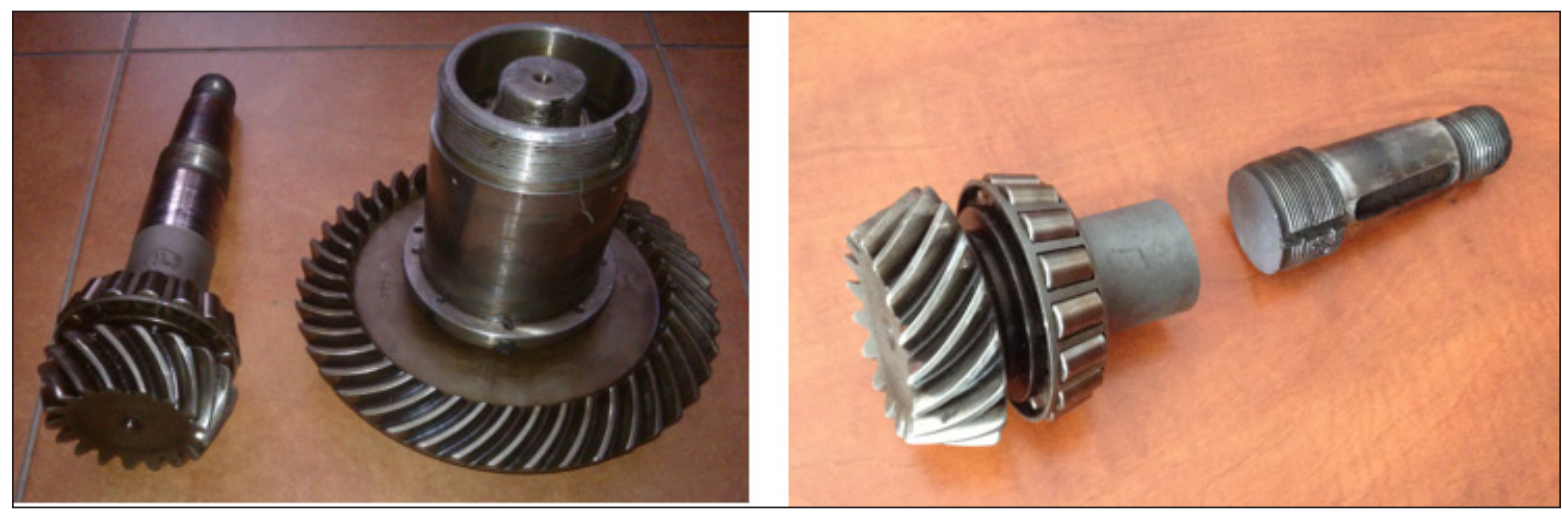

Fig. 3. Exploited toothed wheels taken out of a generator drive gear and an element cut across for laboratory examination [11] 
that hardness limit. This means about 6 times increase of hardness value as compared to that of the substrate on which the coating has been applied.

On the other hand, for the thickness of $20 \mu \mathrm{m}$, 5 times increase was obtained; for $10 \mu \mathrm{m}$ - increase of 4 times, which is also a very good and noticeable effect of the application of the Ni-P coating. Basing on the hardness tests, it can also be stated that the differences result, first of all, from the stiffness of the coatings: the stiffness is lower for smaller thicknesses and that has caused deflection (deformation) of the coating in the place and vicinity of the indentation under the influence of the indenter load. Unfortunately, this is an exceptionally disadvantageous phenomenon, because resistance to surface deformation should be as high as possible, particularly due to the common occurrence of deformation wear of the top layer of machine parts in exploitation. Higher stiffness and deformation resistance is shown by coatings of larger thickness and the same trend is maintained also in the case of puncturing the coating with the indenter of the hardness tester. However, hardness values decrease by almost $50 \%$ for the individual thickness as compared to the Ni-P coatings which were been punctured.

\section{CONCLUSIONS}

1. Small coating thickness do not ensure much increase of the surface macrohardness of a given part, but, with the increase of the coating increase from 10 to $20 \mu \mathrm{m}$, its nanohardness increases by over $100 \mathrm{HV}$; with the increase from 20 to $30 \mu \mathrm{m}$ - by over $200 \mathrm{HV}$.

2. The hardness of the coatings on the aluminum alloy is very high but, after puncturing and destruction of the bond with the surface layer, the hardness rapidly decreases to close to the $\mathrm{Al}$ alloy.

3. The larger thickness of the coating, the higher its stiffness and deformation resistance.

4. Assuming that the bond of the coating with the surface layer is sufficiently strong and the minimum coating thickness properly selected depending to the technical requirements, e.g. on the basis of loads, pressures, friction force, parts fitting etc. the coatings will fulfill their antiwear function in the predicted exploitation conditions and aluminum alloys with antiwear coatings could be an alternative for steel machine parts.
3. Hardness tests do not suffice for the assessment of the coatings in respect of their adhesion to the aluminum alloy and resistance to spalling, e.g. when friction force occurs during contact with another machine element or with cyclic deflection of the coating (fatigue). For that reason, detailed tribological investigation should be performed to determine their suitability in the application for machine parts.

\section{REFERENCES}

1. Krolczyk G.M., Nieslony P., Krolczyk J.B., Samardzic I., Legutko S., Hloch S., Barrans S. and Maruda R.W. Influence of argon pollution on the weld Surface Morphology. Measurement, 70, 2015, 203-213.

2. Krolczyk G.M., Krolczyk J.B., Maruda R.W., Legutko S. and Tomaszewski M. Metrological changes in surface morphology of high-strength steels in manufacturing processes. Measurement, 88, 2016, 176-185.

3. Maruda R.W., Krolczyk G.M., Feldshtein E., Szydlowski M., Legutko S., Pusavec F. and Sobczak-Kupiec A. A study on droplets sizes, their distribution and heat exchange for minimum quantity cooling lubrication (MQCL). International Journal of Machine Tools and Manufacture, 100, 2016, 81-92.

4. Krolczyk G., Legutko S., Nieslony P. and Gajek M. Study of the surface integrity microhardness of austenitic stainless steel after turning. Tehnički Vjesnik - Technical Gazette, 21(6), 2014, 1307-1311,

5. Ozimina D., Madej M. and Senatorski J. Wytwarzanie przeciwzużyciowych warstw powierzchniowych typu Ni-P- $\mathrm{Al}_{2} \mathrm{O}_{3}$. Inżynieria Powierzchni, 4, 2006.

6. Kwiatkowski L and Tomassi P. Powłoki konwersyjne na blachach aluminiowych - technologie wytwarzania i metody badań. Inżynieria powierzchni, 1, 2009.

7. Dudzik K. Analiza możliwości zastosowania zgrzewania tarciowego metodą FSW elementów konstrukcji okrętowych wykonanych ze stopu AlZn5Mg1. Rozprawa doktorska, Gdynia, 2012.

8. Blicharski M. Inżynieria powierzchni, WNT, Warszawa, 2012.

9. Żak T. Poradnik galwanotechnika, WNT, Warszawa, 1985.

10. Burakowski T. Rozważania o synergizmie w inżynierii powierzchni. Wydawnictwo Politechniki Radomskiej, Radom, 2004.

11. Czapczyk K., Suszynski M., Legutko S., Furmanski L. and Grobelny P. Analysis of the application possibility of gears made in aluminum alloy in railway vehicles. Proceedings of 16th International Scientific Conference Automation in Production Planning and Manufacturing (in Polish), Zilina, Slovak Republic, 2015, 33-37. 